\title{
Performance of Wishart Classification Algorithm to Map Mangrove Forest Using Fully Polarimetric Synthetic Aperture Radar at C-, L- and P-bands
}

\author{
Bambang H. Trisasongko and Dyah R. Panuju \\ Department of Soil Science and Land Resources. Bogor Agricultural University. \\ Jalan Meranti. Bogor 16680. Indonesia. \\ trisasongko@live.it
}

\begin{abstract}
Forested landscapes such as mangrove have drawn many attentions due to their importance in carbon stock. Many attempts were conducted to obtain suitable mangrove map using multi-spectral remote sensing imagery. However, atmospheric disturbance including cloud limits multi-spectral sensors. In many cases, observation through Synthetic Aperture Radar (SAR) is then required. In this research, C-, L- and P-band fully polarimetric SAR data were evaluated to provide a mangrove map exploiting Wishart classifier. Results indicated that Ceriops was the only distinguishable species at C-band. Observation using longer wavelengths (L- and P-bands) revealed fairly strong attenuation from soil background. However, overall accuracy suggested that P-band produced lowest classification error, hence it was suitable to produce a highly accurate map.
\end{abstract}

Keywords: Mangrove species, Polarimetry, SAR, Wishart

\section{Introduction}

Geographically, mangroves are distributed in tropical region and dominate most of coastline area. Depending on the extent of warm water from the tropics, mangrove forests are also found in subtropical zones such as southern Australia and New Zealand. Generally, mangroves grow on tropical climate with saline or freshwater environment. Tidal waves are commonly responsible for nutrient supplies and indirectly minimize competition from other vegetations. The tide also plays an important role to transport seedlings, allowing broad distribution of mangrove species.

In an undisturbed environment, mangroves can grow fast and densely populated. Therefore, they provide an ideal and natural protection for coastal region from waves or hurricanes. As the last tsunami hit north Indian Ocean and delivered wide impacts on South East Asian socioeconomics, awareness of the importance of coastal protection has raised. Several schemes can be implemented to minimize disaster's impact. Nevertheless, mangrove forest has a proven record on minimizing impact of tsunami [1]. Due to its uniqueness and biodiversity richness, mangrove has been evaluated as an indicator of coastal environment changes [2].

There has been a strong pressure on mangrove habitat. Aquacultures are probably the most dominant factor responsible to the degradation. In the last two decades, a large number of mangrove conversions have been indicated since the coastal zone is a prime land for shrimp farming. Massive depletion on world's mangrove forest has been reported, including Asia [3]. Valiela et al. [4] estimated about 35\% of mangrove forests have been converted into various uses since 1980s. Both Asia and America regions shared similar percentage of loss, 36\% and $38 \%$ respectively, while Australia lost the least (14\%).

Similarly to other forested sites, assessments on the biophysical properties of mangrove have been presented. For this purpose, remotely sensed data are substantial, for instance on the estimation of leaf area index using optical data [5]. Mentioning data gaps due to cloud cover, Synthetic Aperture Radar (SAR) sensors were also studied to obtain biomass information [6-7].

Received: November $7^{\text {th }}, 2011$. Accepted: October $30^{\text {th }}, 2012$ 
However, basic information such as mangrove species map is rarely available, despite its importance to assist further analysis or field assessment.

SAR polarimetry data have been used to this aim considerably. One of the earliest utilizations was reported by Pasqualini et al. [8] using Shuttle Imaging Radar SIR-C. Based on amplitude data, the accuracy by means of per-pixel classification scheme was fairly moderate. To improve per-pixel classification, incorporating textural information was advised [9]. A mixture of different polarization and wavelength such as ERS and JERS combination was also found useful to improve land cover map of coastal region [10], especially to discriminate highand low-density mangrove from their natural surroundings. Another approach by means of integrating SAR with optical images has been studied as well. Mitchell and Lucas [11], for instance, showed that integration of SAR and hyperspectral sensor provides a better understanding to study mangrove composition. Similarly, Rodrigues and Souza-Filho [12] study in Brazil concluded that wetlands, including general mangrove communities, were able to be mapped by combination of Landsat TM and Radarsat-1.

A paper by Held et al. [13] was probably the earliest attempt to map mangrove species by means of radar polarimetry data. Several mangrove species were successfully identified, including Rhizophora, Bruguiera and Ceriops. All possible frequencies (C-, L- and P-band) of AIRSAR system were explored, in addition to L-band pedestal image. Nevertheless, low accuracy was attained using the AIRSAR only dataset. An appreciable accuracy was achieved only after combining CASI and AIRSAR data. Similar attempts were made by Lucas et al. [14] at several mangrove sites in Australia and Latin America and Pereira et al. [15] utilizing ALOS PALSAR L-band fully polarimetric (PLR) dataset.

Previous reports [10-15] were solely based on the amplitude data. The data type offers a simple, but partial, representation of complex radar data which can be assessed using common image processing techniques. However, the approach disregarded complex polarimetric radar data processing which also contains various interesting information. The purpose of this paper is to evaluate fully polarimetric SAR imagery to present species map of a mangrove forest based on complex fully polarimetric data analysis, in particular using Wishart classification algorithm.

\section{Methodology}

The Daintree (Queensland, Australia) site was recorded by JPL/NASA DC-8 AirSAR system which is able to provide multi-polarimetric and multi-frequency images. The first acquisition was taken in November 1996 which was a subject of previous study [13]. This paper explored the last data capture obtained through PACRIM-II Campaign in August 2000. Both data are available in fully polarimetric set at C- $(5.3 \mathrm{GHz}), \mathrm{L}-(1.2 \mathrm{GHz})$ and P- $(0.4 \mathrm{GHz})$ band. Figure 1 presents the study site taken from high-resolution optical data.

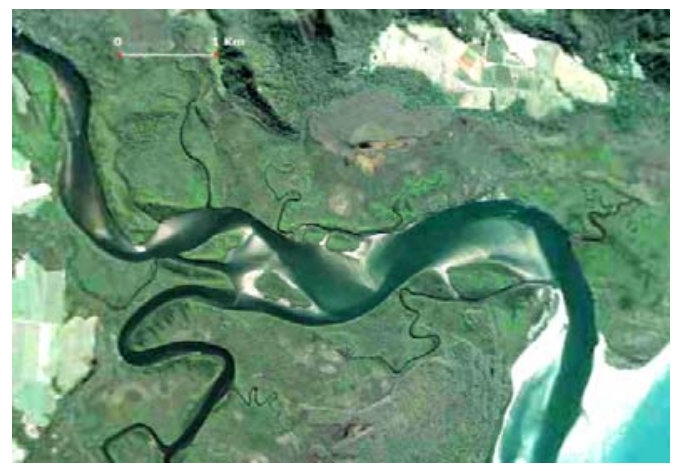

Figure 1. Site location (courtesy of Google Earth). 
Initially, AirSAR raw (compressed Stokes matrix) data were converted into coherence [T3] matrix using a freely-available toolkit namely PolSARPro. This conversion allows preservation of multivariate complex Wishart distribution, which is useful for classification purpose. In addition to covariance [C3] matrix, coherence matrix conveniently represents all components of complex polarimetric data, hence allows exploitation of all available information.

In order to minimize speckle noise in the radar data, filtering by Refined Lee Filter was employed using $5 \times 5$ kernel size. While this size may be subjective, preliminary observation showed that the result was visually optimal. Therefore reducing the noise and maintain clarity between observable boundaries could be taken into account. The AirSAR data were preprocessed by multi-looking, hence the use of minimal size of kernel was sufficient. In this case, applying excessive kernel size might degrade quality of the image.

Visual observation was conducted to observe general responses of surface covers on multifrequency polarimetric signal. A Pauli-composite image for each frequency was constructed to provide color composite figures using following configuration:

$$
\begin{aligned}
& \text { Red }=|\mathrm{S} h h-\mathrm{S} v v| \\
& \text { Green }=|\mathrm{S} h v+\mathrm{S} v h| \\
& \text { Blue }=|\mathrm{S} h h+\mathrm{S} v v|
\end{aligned}
$$

where $h$ and $v$ represents horizontal and vertical polarization respectively; hence Shh denotes component of horizontally transmitted and horizontally received signal. Based on those composite images, the quality of preprocessing previously taken was examined, particularly for speckle noises and the texture information. The step was particularly important since the classification approach was pixel-wise.

Prior to supervised classification, samples were taken with guidance of available thematic map and in-situ data [13]. In addition to water bodies (river and estuary), four vegetative covers were observed i.e. Rhizophora, Bruguiera, Ceriops and Acacia. First three species were recognized as mangrove communities and located in the lowland regions (adjacent to the river or in back-swamp). The Acacia was found in beach ridge (sand dune complex) in southern part of the estuary. The mangroves were scattered in patchy fragments. This imposed small sampling dataset for classification. Two sampling set were taken for each surface cover. The first was used to create classification rule and the second was for accuracy assessment.

Supervised classification was performed through Wishart algorithm [16] utilizing complex fully polarimetric SAR data. Detailed descriptions and processes used in this research were taken from Lee and Pottier [17]. Multilook processing of complex fully polarimetric SAR data can be achieved through spatial averaging of 1-look observations, mathematically denoted as

$$
Z=\frac{1}{n} \sum_{k=1}^{n} \underline{u}(k) \underline{u}(k)^{*} T
$$

where $\mathrm{n}=$ number of looks and $\underline{u}(k)$ is $k$-th complex polarization vector (1-look). The complex polarimetric matrix $\mathrm{A}=n Z$, which has complex Wishart distribution, contains following probability density function

$$
p_{A}(A)=\frac{|A|^{n-q} \exp \left[-\operatorname{Tr}\left(C^{-1} A\right)\right]}{K(n, q)|C|^{n}}
$$

Parameter $q$ denotes dimension of $\underline{u}$, which is 3 for monostatic SAR configuration. Lee et al. [16] proposed following distance measure for classification purpose: 
Bambang H. Trisasongko, et al.

$$
d\left(Z, \omega_{m}\right)=\ln \left|C_{m}\right|+\operatorname{Tr}\left(C_{m}^{-1} Z\right)
$$

where $C_{m}$ denotes covariance matrix (also applicable for coherence matrix) for class $\omega_{m}$. The Wishart distance was then employed to discriminate all designated land cover types.

Finally, quantitative analyses through confusion matrix were computed for each frequency. This allows selection of best SAR frequency. To avoid biases, accuracy was computed using testing data which were comparable in size to training data used for Wishart classification.

\section{Results and Discussion}

A. Responses on polarimetric signal

Pauli decomposition algorithm provides a convenient way to visualize polarimetric data onto a composite image. Another technique namely Sinclair algorithm also offers similar functionality as well. Nevertheless, it appears that the latter was not as popular as Pauli. Figure 2 shows three composite images representing each frequency.

C-band was the shortest wavelength in AirSAR frequency setup. This affects on very limited penetration into vegetative layers and therefore most of the scattering objects were localized to top of canopy (leaves). In general, three different mangrove species were quite indistinguishable. Although Rhizophora is quite similar to Bruguiera in terms of coherence matrix (Table 1), both species were quite distinguishable by $\mathrm{T}_{13}$ component. A notable difference was observed on Ceriops communities due to its sparse distribution. At hyper-saline region (on top of the image), environmental background (clutter) was considerably dominant. Therefore, the tone is reddish and noticeably has different response to both Rhizophora and Bruguiera.

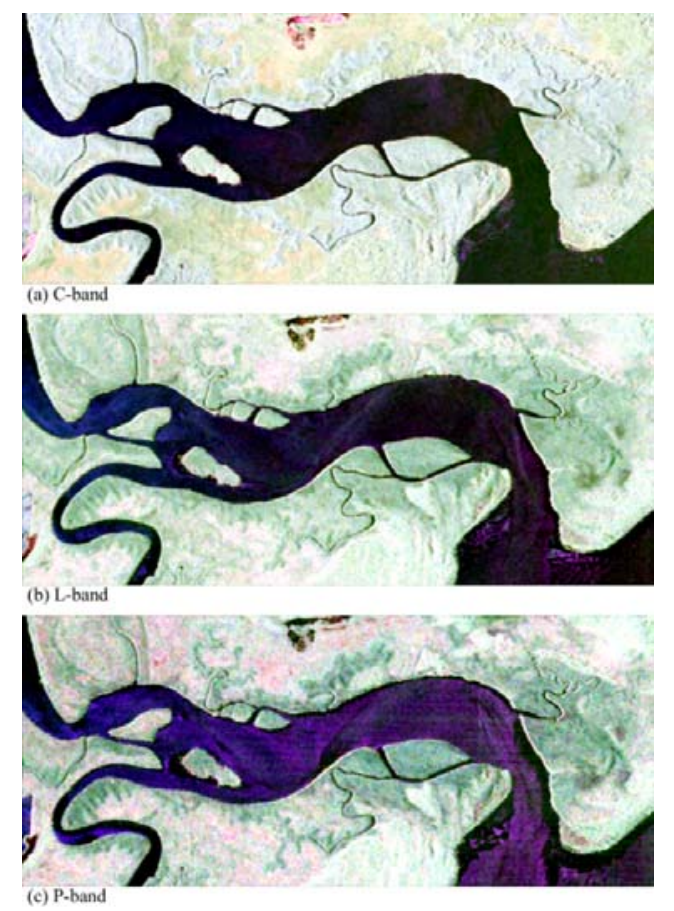

Figure 2. Pauli composite for each band.

On L-band, a greater penetration of signal through canopy can be observed. At this frequency, backscattered signal from the leaves may be small; most returned signals were due to below canopy branches. Ceriops community appears reddish due to its ground reflection and 
sparse distribution. Visual separation was considerably difficult for Rhizophora and Bruguiera mangroves as of C-band data. However, Rhizophora appears darker than Bruguiera. The [T3] matrix suggests this finding where all diagonal components of Bruguiera are slightly higher than Rhizophora. This result indicates high density of branches was observed in Rhizophora species. Those branches in turn created complex and intense interactions with incoming signal, hence low signal was returned to the sensor. As observed in the field, Rhizophora generally has a greater number of branches in comparison to those of Bruguiera.

Table 1. Cluster centers of training dataset. Off-diagonal components are represented in complex number.

\begin{tabular}{llll}
\hline Land Cover & C-Band & L-Band & P-Band \\
\hline Rhizophora & & & \\
$\mathrm{T}_{11}$ & 0.244 & 0.041 & 0.023 \\
$\mathrm{~T}_{12}$ & $-0.008+(-0.013 \mathrm{j})$ & $0.007+(-0.001 \mathrm{j})$ & $0.004+(0.004 \mathrm{j})$ \\
$\mathrm{T}_{13}$ & $-0.007+(-0.002 \mathrm{j})$ & $0.000+(-0.002 \mathrm{j})$ & $0.000+(0.001 \mathrm{j})$ \\
$\mathrm{T}_{22}$ & 0.089 & 0.018 & 0.012 \\
$\mathrm{~T}_{23}$ & $-0.002+(-0.009 \mathrm{j})$ & $-0.001+(0.000 \mathrm{j})$ & $0.000+(0.000 \mathrm{j})$ \\
$\mathrm{T}_{33}$ & 0.059 & 0.015 & 0.006 \\
\hline Bruguiera & & & \\
$\mathrm{T}_{11}$ & 0.256 & 0.048 & 0.038 \\
$\mathrm{~T}_{12}$ & $0.011+(-0.019 \mathrm{j})$ & $0.008+(-0.001 \mathrm{j})$ & $0.013+(0.006 \mathrm{j})$ \\
$\mathrm{T}_{13}$ & $-0.001+(-0.001 \mathrm{j})$ & $-0.001+(0.000 \mathrm{j})$ & $0.000+(0.000 \mathrm{j})$ \\
$\mathrm{T}_{22}$ & 0.085 & 0.024 & 0.034 \\
$\mathrm{~T}_{23}$ & $-0.001+(-0.006 \mathrm{j})$ & $-0.001+(0.000 \mathrm{j})$ & $0.001+(-0.001 \mathrm{j})$ \\
$\mathrm{T}_{33}$ & 0.057 & 0.017 & 0.009 \\
\hline Ceriops & & & \\
$\mathrm{T}_{11}$ & 0.166 & 0.109 & 0.084 \\
$\mathrm{~T}_{12}$ & $0.011+(-0.002 \mathrm{j})$ & $0.034+(0.009 \mathrm{j})$ & $-0.002+(0.015 \mathrm{j})$ \\
$\mathrm{T}_{13}$ & $-0.005+(0.001 \mathrm{j})$ & $0.001+(-0.003 \mathrm{j})$ & $0.000+(0.002 \mathrm{j})$ \\
$\mathrm{T}_{22}$ & 0.123 & 0.087 & 0.113 \\
$\mathrm{~T}_{23}$ & $-0.003+(-0.006 \mathrm{j})$ & $-0.005+(-0.002 \mathrm{j})$ & $0.001+(-0.004 \mathrm{j})$ \\
$\mathrm{T}_{33}$ & 0.064 & 0.039 & 0.019 \\
\hline Acacia & & & \\
$\mathrm{T}_{11}$ & 0.238 & 0.096 & 0.096 \\
$\mathrm{~T}_{12}$ & $-0.014+(-0.007 \mathrm{j})$ & $0.011+(-0.002 \mathrm{j})$ & $0.015+(0.009 \mathrm{j})$ \\
$\mathrm{T}_{13}$ & $0.002+(-0.003 \mathrm{j})$ & $0.004+(0.003 \mathrm{j})$ & $-0.001+(-0.002 \mathrm{j})$ \\
$\mathrm{T}_{22}$ & 0.115 & 0.064 & 0.087 \\
$\mathrm{~T}_{23}$ & $0.000+(-0.007 \mathrm{j})$ & $-0.004+(0.002 \mathrm{j})$ & $0.000+(-0.001 \mathrm{j})$ \\
$\mathrm{T}_{33}$ & 0.075 & 0.049 & 0.035 \\
\hline Water & & 0.010 & $-0.008+(0.003 \mathrm{j})$ \\
$\mathrm{T}_{11}$ & $-0.005+(-0.001 \mathrm{j})$ & $-0.005+(-0.001 \mathrm{j})$ & $-0.001+(0.001 \mathrm{j})$ \\
$\mathrm{T}_{12}$ & $-0.001+(0.000 \mathrm{j})$ & $0.000+(-0.001 \mathrm{j})$ & 0.007 \\
$\mathrm{~T}_{13}$ & 0.007 & 0.003 & $0.001+(0.000 \mathrm{j})$ \\
$\mathrm{T}_{22}$ & $0.000+(0.000 \mathrm{j})$ & $0.000+(0.000 \mathrm{j})$ & 0.001 \\
$\mathrm{~T}_{23}$ & 0.003 & 0.000 & \\
$\mathrm{~T}_{33}$ & & & \\
& & & \\
\hline
\end{tabular}

With a longest wavelength available in AirSAR system, P-band has particular advantage for forestry applications. The signal has capability to obtain under-story information, hence it is 
Bambang $\mathrm{H}$. Trisasongko, et al.

primarily useful to estimate stand biomass [6-7]. Interaction of the signal and dense Rhizophora stand was perceivable; hence the species still appears greenish. Both Bruguiera and Ceriops suffered from soil attenuation. As ground information might be dominant on Pband data, it was clear that sand dunes could be distinguished from the lowland region.

\section{B. Polarimetric classification}

Taking into account available information on the training set, Wishart classification procedure was performed to derive land cover map using 3x3 ensemble averaging. No postclassification procedure was performed to allow more focus on classification capability. Figure 3 presents Wishart classified images of each frequency.

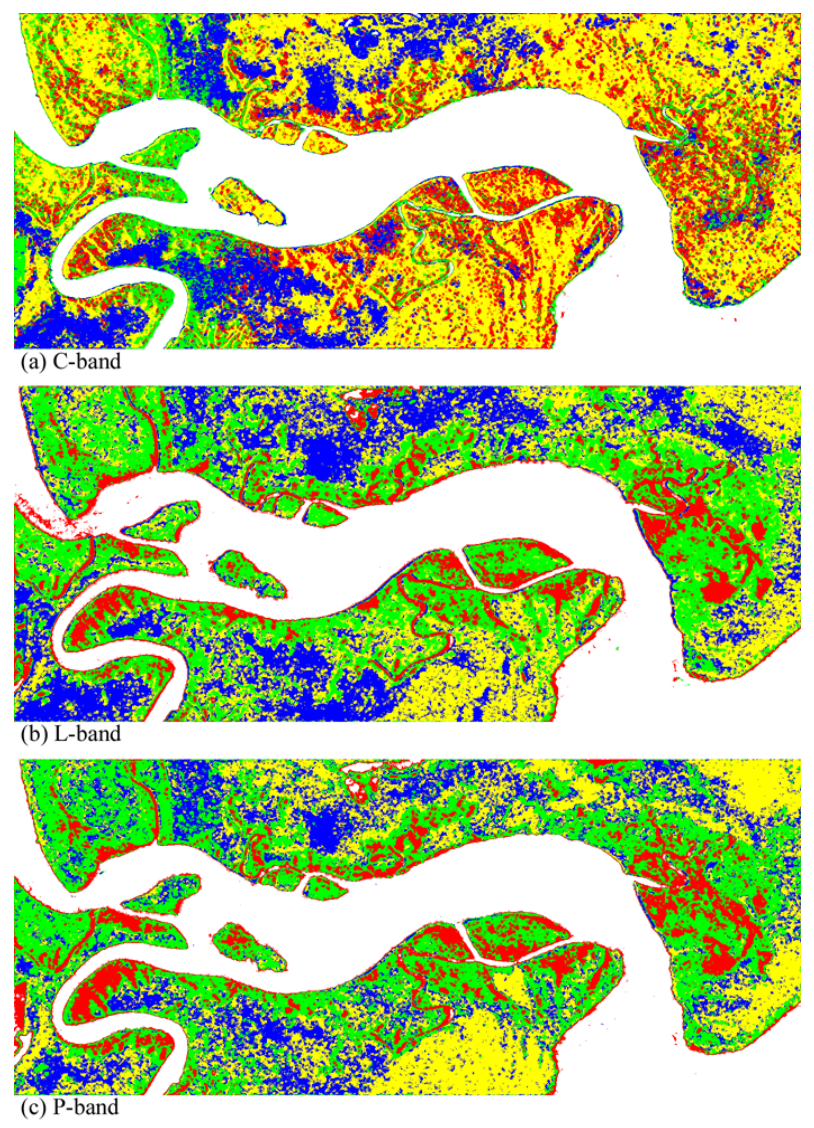

Figure 3. Wishart classification. Color code: red=Rhizophora, green=Bruguiera, blue=Ceriops, yellow=Acacia, white $=$ water.

In all images, fragmented spatial configurations are visible. As AirSAR system produced high-resolution dataset with pixel spacing about 3.3 and 4.6 meters for range (East-West, left to right on the image) and azimuth (North-South) direction respectively, textural information was revealed. The Wishart classification was based on tone data processing hence the textural information was neglected. As a result, high variability in single mangrove community is clearly seen in the figures. Nevertheless, an appreciable grouping can be found in Rhizophora at L- and P-band. Acacia community over sand dunes was also significantly determined. A fair contiguity was observable on Bruguiera and Ceriops forests. Despite difficulties on classification due to texture information, impartial spatial contiguity can be observed in general. This suggests adequate accuracy on the classification procedure which will be discussed in the rest of this section. 
In order to derive quantitative performance, three confusion matrices were computed. Table 2-4 respectively shows accuracy assessment at C-, L- and P-band. Generally, accuracies were suitable based on testing data. Overall classification accuracy for C-, L- and P-band was 77.88\%, 83.83\% and $91.00 \%$ respectively. While accuracy improvement was fairly insignificant using short wavelengths, low frequency radar data such as P-band contributed significantly to lower misclassification bias. It suggests that $\mathrm{P}$ band was the most suitable data to map the area.

Applying longer wavelength significantly improved to the detection of Rhizophora. At Cband, it was clear that the species had higher degree of confusion to other species having relatively thick canopy such as Acacia and Bruguiera. By employing L- or P-band, improvement on the classification accuracy was achieved which took benefit of below-canopy structural differences between those species. Bruguiera and Acacia gained similar advantages of exploiting longer wavelengths.

In contrast, Ceriops appeared insensitive to longer wavelengths. On longer wavelength, an increasing confusion was shown between Ceriops and Acacia. This suggested similarity of under-canopy structure between both species. Returned signal from these covers revealed contribution of soil background due to sparse canopy and branches.

Nevertheless, applicability of P-band for routine monitoring has been questionable. Despite its valuable capability, mounting a P-band radar system into a spaceborne platform is rather difficult due to power constraints and the opacity of atmosphere [18]. In addition, frequent observations by using recent airborne polarimeter systems are also difficult due to limited airborne platforms. Proposals to establish P-band SAR have been launched including BIOMASS [19] and Ecosar [20]. However, referring to the result, potentially data provider in the near future would be Japanese ALOS PALSAR-2 which operates at L-band. Canadian Radarsat-2 which employs C-band might be applicable for other mangrove species. Nevertheless, limited penetration on thick canopy of mangrove may limit utilization of the thematic products.

Table 2. Confusion matrix on C-band. Column represents reference classes. RH=Rhizophora;

\begin{tabular}{llllll}
\multicolumn{5}{c}{ BR=Bruguiera; $\mathrm{CE}=$ Ceriops; $\mathrm{AC}=$ Acacia WA=Water } \\
\hline & RH & BR & CE & AC & WA \\
\hline RH & 55.69 & 18.53 & 1.49 & 24.29 & 0.00 \\
BR & 13.53 & 73.49 & 3.30 & 9.68 & 0.00 \\
CE & 2.43 & 0.87 & 87.98 & 8.73 & 0.00 \\
AC & 17.18 & 3.94 & 6.65 & 72.23 & 0.00 \\
WA & 0.00 & 0.00 & 0.00 & 0.00 & 100.00 \\
\hline
\end{tabular}

Table 3. Confusion matrix on L-band. Column represents reference classes. RH=Rhizophora;

\begin{tabular}{llllll}
\multicolumn{5}{c}{ BR=Bruguiera; $\mathrm{CE}=$ Ceriops; $\mathrm{AC}=$ Acacia WA=Water } \\
\hline & RH & BR & CE & AC & WA \\
\hline RH & 74.58 & 25.32 & 0.05 & 0.05 & 0.00 \\
BR & 28.25 & 70.50 & 0.08 & 1.18 & 0.00 \\
CE & 0.00 & 1.33 & 83.82 & 14.86 & 0.00 \\
AC & 0.00 & 0.00 & 9.71 & 90.29 & 0.00 \\
WA & 0.00 & 0.00 & 0.00 & 0.00 & 100.00 \\
\hline
\end{tabular}


Bambang $\mathrm{H}$. Trisasongko, et al.

Table 4. Confusion matrix on P-band. Column represents reference classes. $\mathrm{RH}=$ Rhizophora;

\begin{tabular}{llllll}
\multicolumn{5}{c}{ BR=Bruguiera; $\mathrm{CE}=$ Ceriops; $\mathrm{AC}=$ Acacia WA=Water } \\
\hline & $\mathrm{RH}$ & $\mathrm{BR}$ & $\mathrm{CE}$ & $\mathrm{AC}$ & $\mathrm{WA}$ \\
\hline $\mathrm{RH}$ & 92.02 & 7.98 & 0.00 & 0.00 & 0.00 \\
$\mathrm{BR}$ & 5.66 & 92.60 & 1.73 & 0.00 & 0.00 \\
$\mathrm{CE}$ & 0.00 & 2.08 & 82.31 & 15.61 & 0.00 \\
$\mathrm{AC}$ & 0.00 & 0.00 & 11.94 & 88.06 & 0.00 \\
$\mathrm{WA}$ & 0.00 & 0.00 & 0.00 & 0.00 & 100.00 \\
\hline
\end{tabular}

\section{Conclusion}

In summary, a new experiment on mangrove species mapping by means of fully polarimetric radar data is presented. Visual analysis based on Pauli composite image showed confusion on discriminating different vegetation species through shorter wavelengths such as C-band. On P-band, straightforward separation between mangrove communities was found. This research also observed that delimitation of upland region (sand dune complex) form surrounding wetland was possible. Assisted by Wishart classification algorithm, fairly high accuracies i.e. $77.88 \%, 83.83 \%$ and $91.00 \%$ for C-, L- and P-band were obtained. The quantitative analysis confirmed visual observation and implies that longer wavelength radar data provided a greater accuracy on the thematic map.

\section{Acknowledgements}

The authors would like to thank AirSAR team of JPL/NASA for provision of radar polarimetric data. Part of the research was taken at the School of Physical, Environmental and Mathematical Sciences, University of New South Wales at the Australian Defence Force Academy. Former Prof. Brian Lees and Dr. David Paull are thanked for their assistance in literature review.

\section{References}

[1] F. Dahdouh-Guebas, L. P. Jayatissa, D. Di Nitto, J. O. Bosire, D. Lo Seen and N. Koedam, "How effective were mangroves as a defence against the recent tsunami," Curr. Biol., vol. 15, pp. R443-R447, DOI: 10.1016/j.cub.2005.06.008, 2005.

[2] F. Blasco, P. Saenger and E. Janodet, "Mangroves as indicators of coastal changes," Catena, vol. 27, pp. 167-178, DOI: 10.1016/0341-8162(96)00013-6, 1996.

[3] F. Blasco, M. Aizpuru and C. Gers, "Depletion of the mangroves of Continental Asia," Wetl. Ecol. Manage., vol. 9, pp. 245-256, DOI: 10.1023/A:1011169025815, 2001.

[4] Valiela, J.L. Bowen and J.K. York, "Mangrove forests: one of the World's threatened major tropical environments,” Biosci, vol. 51, pp. 807-815, DOI: 10.1641/00063568(2001)051[0807:MFOOTW]2.0.CO;2, 2001.

[5] B.M. Diaz and G.A. Blackburn, "Remote sensing of mangrove biophysical properties: evidence from a laboratory simulation of the possible effects of background variation on spectral vegetation indices,” Int. J. Rem. Sens., vol. 24, pp. 53-73, DOI: 10.1080/01431160305012, 2003.

[6] E. Mougin, C. Proisy, G. Marty, F. Fromard, H. Puig, J.L. Betoulle and J.P. Rudant, "Multifrequency and multipolarization radar backscattering from mangrove forests," IEEE Trans. Geosci. Rem. Sens., vol. 37, pp. 94-102, DOI: 10.1109/36.739128, 1999.

[7] C. Proisy, E. Mougin, F. Fromard, V. Trichon and M.A. Karam, "On the influence of canopy structure on the radar backscattering of mangrove forest," Int. J. Rem. Sens., vol. 23, pp. 4197-4210, DOI: 10.1080/01431160110107725, 2002.

[8] V. Pasqualini, J. Iltis, N. Dessay, M. Lointier, O. Guelorget and L. Polidori, "Mangrove mapping in North-Western Madagascar using SPOT-XS and SIR-C radar data," Hydrobiologia, vol. 413, pp. 127-133, DOI: 10.1023/A:1003807330375, 1999.

[9] B.H. Trisasongko, "Tropical Mangrove Mapping Using Fully-Polarimetric Radar Data," ITB J. Sci., vol. 41A, pp. 98-109, DOI: 10.5614/itbj.sci.2009.41.2.4, 1999. 
[10] M. Simard, G. De Grandi, S. Saatchi and P. Mayaux, "Mapping tropical coastal vegetation using JERS-1 and ERS-1 radar data with a decision tree classifier,” Int. J. Rem. Sens., vol. 23, pp. 1461-1474, DOI: 10.1080/01431160110092984, 2002.

[11] Mitchell and R.M. Lucas, "Integration of aerial photography, hyperspectral and SAR data for mangrove characterization,” Proc. Int. Geosci. Rem. Sens. Symp., vol. 5, pp. 21932195, DOI: 10.1109/IGARSS.2001.977946, 2001.

[12] S.W.P. Rodrigues and P.W.M. Souza-Filho, "Use of multi-sensor data to identify and map tropical coastal wetlands in the Amazon of Northern Brazil," Wetlands, vol. 31, pp. 11-23, DOI: 10.1007/s13157-010-0135-6, 2011.

[13] Held, C. Ticehurst, L. Lymburner and N. Williams, "High resolution mapping of tropical mangrove ecosystems using hyperspectral and radar remote sensing,” Int. J. Rem. Sens., vol. 24, pp. 2739-2759, DOI: 10.1080/0143116031000066323, 2003.

[14] R.M. Lucas, P. Bunting, D. Clewley, C. Proisy, P.W.M. Souza Filho, K. Viergever, I. Woodhouse, C. Ticehurst, J. Carreiras, A. Rosenqvist, A. Accad and J. Armston, "Characterisation and monitoring of mangroves using ALOS PALSAR data," Kyoto/Carbon Phase 1 Report. Available at hhtp://www.eorc.jaxa.jp/ALOS/en/Kyoto/phase_1/KC-Phase1-report_Lucas_WT.pdf. No date.

[15] F.R.S. Pereira, M. Kampel and M. Cunha-Lignon, "Mapping of mangrove forests on the southern coast of Sao Paulo, Brazil, using synthetic aperture radar data from ALOS/PALSAR,” Rem. Sens. Lett., vol. 3, pp. 567-576, DOI: 10.1080/01431161.2011.641511, 2012.

[16] J.S. Lee, M.R. Grunes and R. Kwok, "Classification of multi-look polarimetric SAR imagery based on complex Wishart distribution,” Int. J. Rem. Sens., vol. 15, pp. 22992311, DOI: 10.1080/01431169408954244, 1994.

[17] J-S. Lee and E. Pottier, Polarimetric radar imaging: from basics to applications, Boca Raton, FL, USA: CRC Press, 2009.

[18] K.C. Carver, C. Elachi and F.T. Ulaby, "Microwave remote sensing from space,” Proc. IEEE, vol. 73, pp. 970-996, DOI: 10.1109/PROC.1985.13230, 1985.

[19] K. Scipal, M. Arcioni, J. Chave, J. Dall, F. Fois, T. LeToan, C-C. Lin, K. Papathanassiou, S. Quegan, F. Rocca, S. Saatchi, H. Shugart, L. Ulander and M. Williams, "The BIOMASS mission - An ESA earth explorer candidate to measure the biomass of the earth's forests," Proc. Int. Geosci. Rem. Sens. Symp., pp. 52-55, DOI: 10.1109/IGARSS.2010.5648979, 2010.

[20] T. Fatoyinbo, R.F. Rincon, G. Sun and K.J. Ranson, "Ecosar: A P-band digital beamforming polarimetric interferometric SAR instrument to measure ecosystem structure and biomass,” Proc. Int. Geosci. Rem. Sens. Symp., pp. 1524-1527, DOI: 10.1109/IGARSS.2011.6049358, 2011.

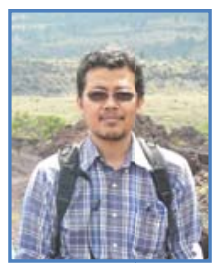

Bambang H. Trisasongko is with Bogor Agricultural University, lecturing remote sensing, especially on Synthetic Aperture Radar (SAR) applications in agriculture, forestry and geosciences.

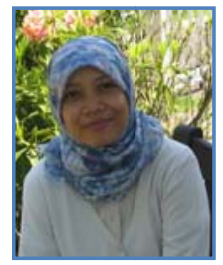

Dyah R. Panuju is a lecturer at the same university, with specialization in quantitative methods and land use planning. 